\title{
EVALUATION OF OPEN REDUCTION AND INTERNAL FIXATION OF DISPLACED INTRA-ARTICULAR FRACTURE OF CALCANEUM-A SHORT TERM STUDY
}

\author{
Jha $R K^{1^{*}}$, Thapa $S^{2}$
}

\section{Affiliation}

1. Assistant professor, Department of orthopedics, Nobel medical college, Biratnagar, Nepal.

2. Lecturer, Department of orthopedics, Nobel medical college, Biratnagar,Nepal.

\section{ARTICLE INFO}

$$
\begin{aligned}
& \text { Received : } 28 \text { July, } 2020 \\
& \text { Accepted : } 25 \text { November, } 2020 \\
& \text { Published : } 22 \text { December, } 2020
\end{aligned}
$$

(c) Authors retain copyright and grant the journal right of first publication with the work simultaneously licensed under Creative Commons Attribution License CC - BY 4.0 that allows others to share the work with an acknowledgment of the work's authorship and initial publication in this journal.

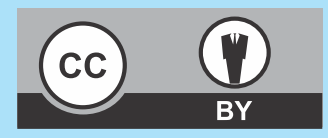

\section{ORA 210}

DOI: https://doi.org/10.3126/bjhs.v5i3.33701

\section{* Corresponding Author}

Dr. Ranjib Kumar Jha

Assistant Professor

Department of Orthopedics

Nobel Medical College and Teaching Hospital, Biratnagar

Email ID: ranjib.k30@gmail.com

ORCID ID: https://orcid.org/0000-0002-4708-3347

\section{Citation}

Jha RK, Thapa S. Evaluation of open Reduction and Internal Fixation of Displaced Intra-articular Fracture of Calcaneum-a Short Term Study. BJHS 2020;5(3)13. 1215-1219.

\section{ABSTRACT}

\section{Introduction}

Management of displaced intraarticular fracture of calcaneum is controversial. Non-operative management often have unsatisfactory result due to subtalar arthritis and abnormal foot morphology.

\section{Objective}

The objective of the study was to evaluate clinical and radiological outcome of patients with displaced intraarticular fracture of calcaneum treated by open reduction and internal fixation(ORIF) with plates and screws through extensile lateral approach.

\section{Methodology}

This was prospective clinical study conducted in Nobel Medical College between November 2016 to December 2019. The patients were treated by ORIF with calcaneal plates and screws through extensile lateral approach. Patients were followed up for minimal one year. Patients were evaluated clinically by using AOFAS hind foot score and radiologically by measuring Bohler's and Gissane angle and calcaneal height and width.

\section{Results}

Out of total 26 cases, fifteen were sander's type II, eight were type III and three were type IV. The mean age of patients was 33.92 years. The mean delay of surgery due to swelling was $8.65 \pm 1.95$ days. The average follow-up period was 17 months. The mean AOFAS hind foot score was 85.08 \pm 7.67 . Ten patients $(38.46 \%)$ had excellent, twelve patients(48.61\%) had good and four patients(15.38\%) had fair outcome. There were significant association between improvement in Bohler's and Gissane angle and functional outcome measured by AOFAS hind foot score.

\section{Conclusion}

Open reduction and internal fixation of displaced intraarticular fracture of calcaneum with calcaneal plates and screws through extensile lateral approach produce good clinical and radiological result.

\section{KEY WORDS}

Calcaneus, intraarticular fracture, open reduction 


\section{INTRODUCTION}

Calcaneal fractures are the most common tarsal bone fracture, which accounts for $1 \%$ to $2 \%$ of overall fracture of body. Most of the calcaneal fracture are intra articular (75\% of calcaneal fracture) and are caused by high energy axial trauma, most commonly due to fall from height and road traffic accidents. ${ }^{1-4}$ The high energy trauma is correlated with soft tissue injury and swelling of foot and frequent associated injury to other part of body.

Displaced intra-articular fracture of calcaneum may lead to debilitating problem for a patient and confusion for most orthopedic surgeon about the best way of management, because the treatment of calcaneal fracture is still controversial. ${ }^{6}$ Because of poor results associated with nonoperative management secondary to subtalar arthrosis and abnormal hind foot morphology, many surgeons advocate for surgical treatment for these fractures. ${ }^{4,7}$ The surgical methods for treatment of calcaneal fracture are open reduction and internal fixation with calcaneal plate and screws, open reduction via less invasive sinus tarsi approach, closed reduction and percutaneous screw fixation and arthroscopic assisted fixation. ${ }^{7}$ Although there are many surgical options, open reduction and internal fixation by extensile lateral approach is considered as gold standard for surgical treatment of displaced intra-articular calcaneal fracture, because anatomic reduction and restoration of calcaneal morphology are easy to achieve, which is important to achieve good functional outcomes.

The available literature gives conflicting evidence supporting both operative and non-operative treatment of intraarticular fractures of the calcaneum. There are very few studies published in our part of world regarding operative management of displaced intra-articular fracture of calcaneum. This study aims to evaluate clinical and radiological outcome of patients with displaced intraarticular fracture of calcaneum treated by open reduction and internal fixation with plates and screws through extensile lateral approach.

\section{METHODOLOGY}

This is prospective study done between November 2016 to December 2019. Total 26 cases with displaced intra-articular fracture of calcaneum, who presented to emergency or outpatient department of orthopedic and trauma of Nobel medical college meeting inclusion criteria and available for at least 12 month of follow up were enrolled in this study. The study was approved by ethical committee of this institute. The patients having age between 18 to 60 years with unilateral displaced intra-articular fracture (articular step off of more than $2 \mathrm{~mm}$ ) of calcaneum (sanders type II, III and IV) were included in the study. The exclusion criteria were open fracture, bilateral calcaneal fracture, signs of compartment syndrome, peripheral vascular disease, local skin infection, neurologic deficit following associated head or spinal injury, other associated fracture of ipsilateral or contralateral lower limb.

Preoperative evaluation was done clinically to see local skin condition and to rule out associated injuries. The anteroposterior, lateral and axial views of calcaneum were obtained(fig.1). CT scan and 3-dimensional(3D) reconstruction were performed to see details and to classify fracture based on sanders classification(fig.2.). ${ }^{10}$ The limb was immobilized in short posterior slab, elevated and ice pack was applied to decrease swelling. Surgery was done, once swelling decreased and wrinkle sign appeared.
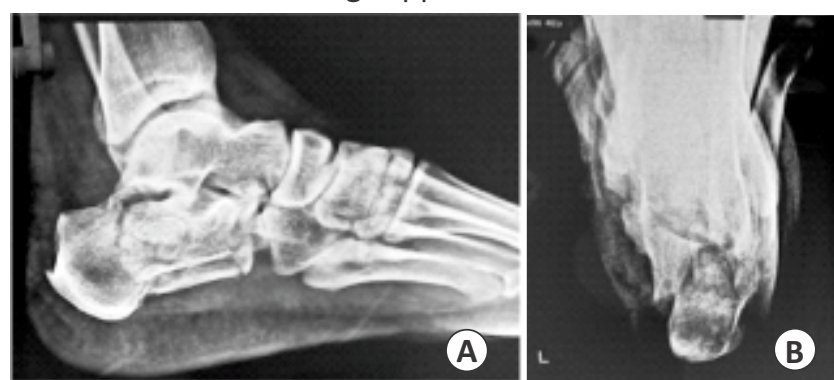

Figure.1. Pre-operative X-rays of calcaneal fracture.(A) Lateral views showing intra-articular fracture of calcaneum with Bohler's angle of 4 degree and Gissane angle of 138 degree. (B) Axial view showingvarus, decrease in height and widening of calcaneum.

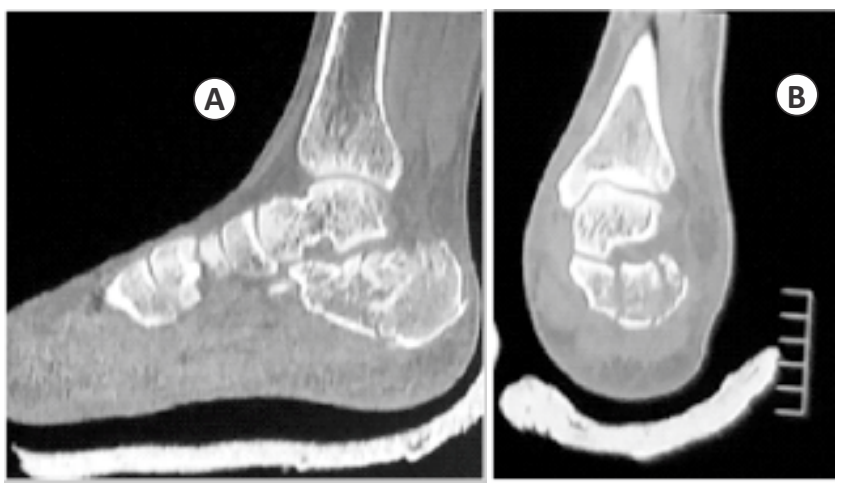

Figure 2: Preoperative CT scan of calcaneal fracture. (A) saggital section of calcaneum. (B) coronal section through posterior facet showing sander's type III calcaneum fracture.

\section{Operative procedure}

Once the patients were under anesthesia, thigh tourniquet was applied. The patients were placed in lateral position with fractured limb up and ankle and foot placed at the end of table, so that intraoperative $\mathrm{C}$-arm could be used easily to see lateral and axial views. The incision and operative technique were used as those described by Eastwood et al. ${ }^{11} \mathrm{An}$ L-shaped incision was given with vertical arm beginning approximately $1 \mathrm{~cm}$ anterior to the Achilles tendon and 2 to $3 \mathrm{~cm}$ proximal to lateral malleolus. The incision was extended distally to the junction between lateral skin and plantar skin and then coursed horizontally towards the base of $5^{\text {th }}$ metatarsal (fig.3A). Full thickness periosteal cutaneous flap was raised by subperiosteal dissection with knife. To minimize trauma to tissue flap, no touch technique retraction was used, in which raised flap were retracted by three $2 \mathrm{~mm}$ kirschnerwires placed in talus, exposing the entire length of calcaneum. By transcalcaneal approach the medial wall was reduced, followed by reduction of intra-articular fragments on to the sustentacular fragment using temporary kirschner wires (fig 3B). The reduction was confirmed visually though 
subtalar joint by inverting foot, and radiologically by lateral and axial views using C-arm. Final stabilization was done by using branched calcaneal plate of appropriate size (fig3C,D) without any use of bone graft. Wound was closed in two layers over no.8French closed suction drain. The ankle and
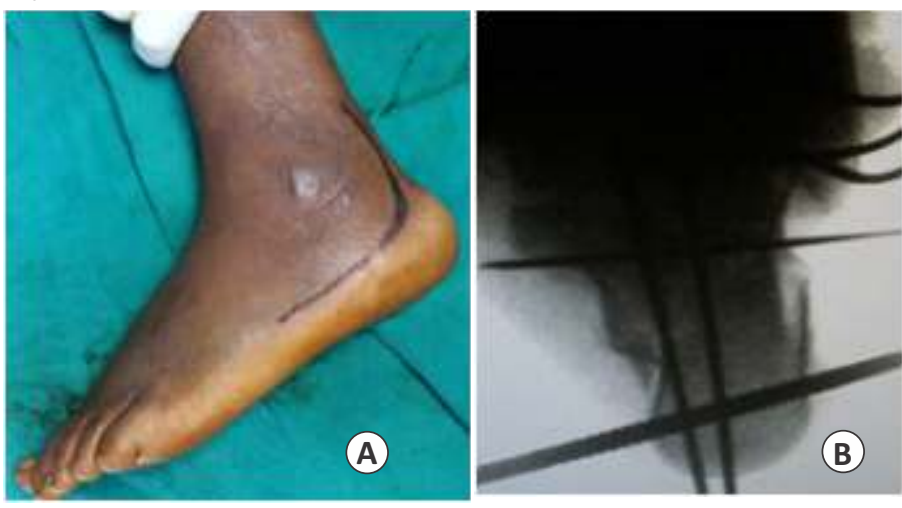

height were measured for radiographic evaluation (fig.4). At the last follow up visit, the patients were asked to complete the American Orthopedic Foot and Ankle(AOFAS) hind foot score questionnaire. ${ }^{12}$ The results were graded as excellent when the score ranged between 90 to 100 , good when it

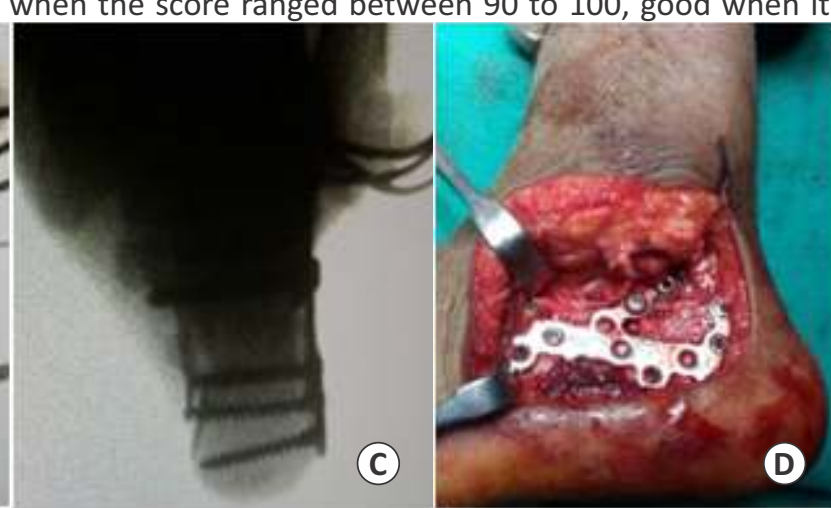

Figure.3: A. Proposed skin marking, B. intraoperative c-arm picture of temporary fixation with kirschner wires after reduction of fracture, $C$ and $D$. after final fixation of fracture.

foot were immobilized with short leg posterior slab.

Post-operatively ankle and foot were elevated and toes movement were encouraged to decrease swelling. After $48 \mathrm{hrs}$, wound was inspected and drain was removed. Patients were mobilized with crutches with non-weight bearing on fractured limb and intermittent ankle and subtalar range of motion exercises were started as soon as pain subsided. The patients were discharged after 5 to 7 was between 80 to 90 , fair when ranged between 70 to 79 and poor when below 69.

Statistical analysis was done using mean, standard deviation, percentage and correlation between radiological and functional outcome found by using Wilcoxon paired test. A p-value $<0.05$ was taken as threshold of statistical significance.
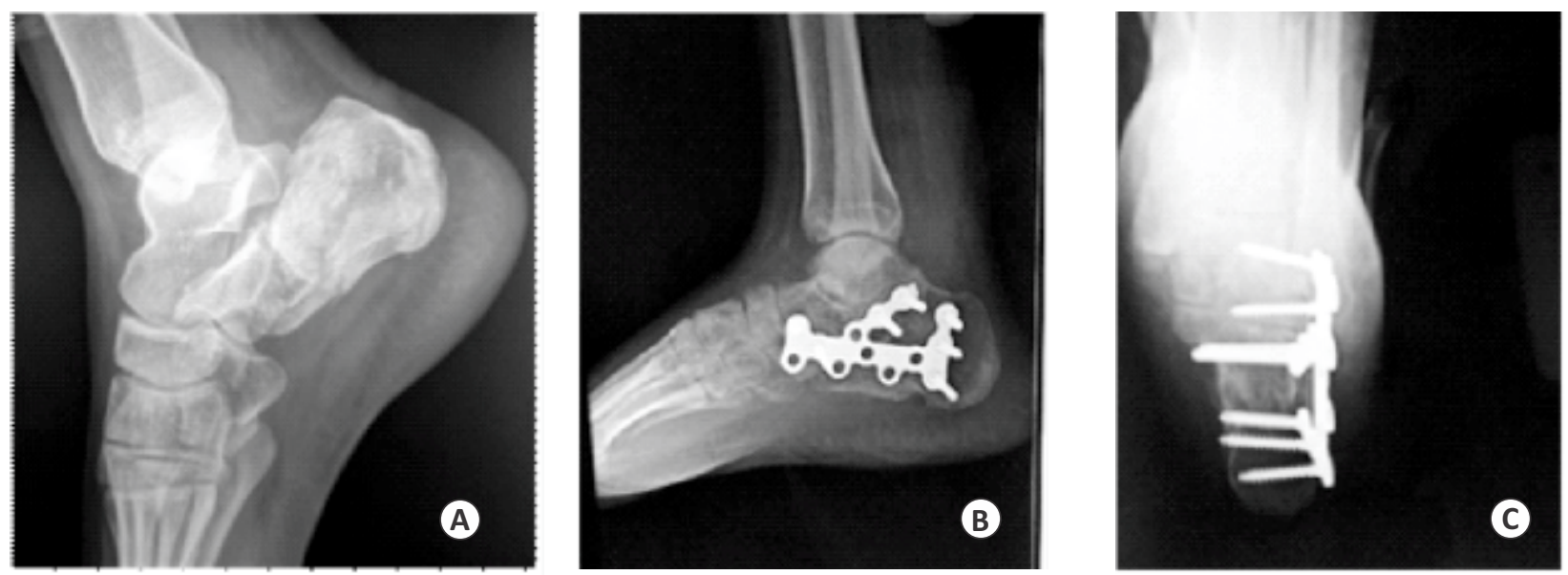

Figure 4: preoperative and postoperative radiographs of healed left calcaneal fracture of 31years male.(A)preoperative lateral radiograph showing collapse of calcaneum with Bohler's angle $8^{\circ}$ and Gissane angle $146^{\circ}$.(B and C) lateral and axial radiographs after healing of fracture with Bohler's and Gissane angle $38^{\circ}$ and $115^{\circ}$ respectively.

post-operative days with advice of suture and short leg posterior slab removal on fourteenth day. The patients were followed up at 6 weeks, 12 weeks and then every 3months for at least 12 months. In each follow up visit, clinical and radiological assessment were performed and any complications, if present, were recorded. Progressive weight bearing started after 6weeks, and full weight bearing was allowed after 12 weeks, provided good radiological signs of healing.

\section{Outcome measurement}

In preoperative and postoperative radiographs at final follow up, Bohler's angle, Gissaneangle, calcaneal width and

\section{RESULTS}

A total of 26 cases were included and available for final follow up, out of which twenty-two were male and four were female(5.5:1). The mean age was 33.92 years, ranging from 20 to 58 years. In 14 cases, the right side was involved (53.8\%) and in 12 cases, the left side was involved (46.2\%). In twenty-two patients, mode of injury was fall from height and in remaining four patient had road traffic accident. The mean delay of surgery was 8.65 days after trauma ranging from 6 to 13 days because of swelling. The average final follow up was 17 months after operation with range of 12 to 24 months. Out of 26 cases, there were 15 sanders type II, 8 sanders type III and three were sanders type IV (Table.1). 


\begin{tabular}{|c|c|}
\hline $\begin{array}{l}\text { Table 1: Patients characteristics } \\
\text { Characteristics }\end{array}$ & Value \\
\hline Age & Mean: $33.92 \pm 9.46$ years \\
\hline $\begin{array}{l}\text { Sex } \\
\text { Male } \\
\text { Female }\end{array}$ & $\begin{array}{l}22(84.6 \%) \\
4(13.4 \%)\end{array}$ \\
\hline $\begin{array}{l}\text { Sidedness } \\
\text { Right } \\
\text { Left }\end{array}$ & $\begin{array}{l}14(53.8 \%) \\
12(46.2 \%)\end{array}$ \\
\hline $\begin{array}{l}\text { Mechanism of injury } \\
\text { Fall from height } \\
\text { Road traffic accident }\end{array}$ & $\begin{array}{l}22(84.6 \%) \\
4(13.4 \%)\end{array}$ \\
\hline $\begin{array}{l}\text { Type of fracture } \\
\text { Sanders type II } \\
\text { Sanders type III } \\
\text { Sanders type IV }\end{array}$ & $\begin{array}{l}15(57.7 \%) \\
8(30.7 \%) \\
3(11.6 \%)\end{array}$ \\
\hline $\begin{array}{l}\text { Intervalbetween trauma to surgery } \\
\text { Union time } \\
\text { Follow up }\end{array}$ & $\begin{array}{l}\text { Mean: } 8.65 \pm 1.95 \text { days } \\
\text { Mean: } 9.69 \pm 2.01 \text { weeks } \\
\text { Mean: } 17.04 \pm 3.06 \text { months }\end{array}$ \\
\hline
\end{tabular}

The average AOFAS hind foot score was $85.08 \pm 7.67$ (range 70 to 96$)$. Out of 26 cases, ten patients $(38.46 \%$ ) had excellent, twelve(48.61\%) patients had good and four(15.38\%) patients had fair outcome. There was significant correlation between improvement in Bohler's and Gissane angle and functional outcome(Table 2). Similarly, there were improvement in calcaneal height and width (table 3 ).

Table 2: Relation of Bohler's and Gissane angle with functional outcome

\begin{tabular}{|c|c|c|c|c|}
\hline \multicolumn{4}{|c|}{ AOFAS hind foot score outcome } & P-value \\
\hline Bohler's angle & Excellent $(n=10)$ & Good(n=12) & Fair(n=4) & \multirow{3}{*}{$\begin{array}{l}\mathrm{P}<0.001 \\
\text { Wilcoxon } \\
\text { matched } \\
\text { pair test }\end{array}$} \\
\hline Pre-op & 7.27 & 5.55 & 3.75 & \\
\hline Post-op & 29.73 & 26.73 & 23.5 & \\
\hline Gissane angle & Excellent $(n=10)$ & Good(n=12) & Fair(n=4) & \multirow{3}{*}{$\begin{array}{l}P<0.001 \\
\text { Wilcoxon } \\
\text { matched } \\
\text { pair test }\end{array}$} \\
\hline Pre-op & 140.09 & 134.64 & 142.5 & \\
\hline Post-op & 112 & 102.73 & 108.75 & \\
\hline
\end{tabular}

Table 3: Change in height and width of calcaneum

\begin{tabular}{|l|c|c|}
\hline \multirow{2}{*}{ Calcaneal height } & Preoperative & Postoperative \\
\cline { 2 - 3 } & $39.08 \pm 1.56 \mathrm{~mm}$ & $48.16 \pm 1.79 \mathrm{~mm}$ \\
\hline Calcaneal width & $44.30 \pm 1.82 \mathrm{~mm}$ & $39.18 \pm 1.63 \mathrm{~mm}$ \\
\hline
\end{tabular}

Total five patients developed complications, out of which three had superficial wound infection and two had subtalar joint synovitis. Out of three infection cases, one had minimal marginal skin necrosis as well but all improved with local wound care by dressing and antibiotics. Two subtalar joint synovitis subsided with intra-articular steroid injection.

\section{DISCUSSION}

There is conflicting evidence regarding the benefits of operative intervention over nonoperative treatment of displaced intraarticular fracture of calcaneum. However, non-operative management frequently leads to delayed reconstruction of malunited fracture causing painful and stiff foot, which may lead to delay or permanently loss from returning to previous activities or work. The risk of requirement of subtalar arthrodesis is six time higher in nonoperatively treated than operatively treated calcaneal fracture. ${ }^{4,15}$ Several studies have observed that operatively treated patients had better functional outcome score and less pain than non-operatively treated patients..$^{9,13-15}$ Better understanding of pathoanatomy of calcaneal fracture with help of CT scan and improvement in surgical technique and skills of orthopedic surgeon have increased the scope for surgical treatment of calcaneal fracture.

Because of risk of wound dehiscence and infection, open reduction and internal fixation is always delayed. In our study, patients were operated once swelling subsided and wrinkling of skin appeared. The average delay of surgery from injury time in this study was 8.6 days with range from 6 to 13 days. In a study done by Court-Brown et al, the average delay to surgery was 5.2 (range 1 to 21 )days. ${ }^{16}$ They also observed that delaying surgery was not associated with a lower infection rate. In studies done by Lakhey et al and Shrestha et al in Nepal, the mean delay of surgery were 11.8 (range 10 to 15 ) days and a mean of 7 (range 1to 19) days respectively. ${ }^{17,18}$

In this study of 26 cases, excellent and good results were seen in $84.6 \%$ of patients with mean AOFAS hind foot score $85.08 \pm 7.67$ (range 70 to 96 ). Our finding is comparable to other previously published studies. ${ }^{17,18}$ In a study done by Jain et al, in 28 patients ( 26 unilateral and 2 bilateral) with average follow up of 14.5 months, the average AOFAS score was $86.3 \%$, with $86 \%$ having excellent to good results. ${ }^{19}$ In another retrospective long term(average 10 years) review of 45 patients of displaced calcaneal fracture by Makki et al, excellent to good results were present in $75 \%$ of patients. ${ }^{20}$

In our study, we found positive correlation between functional outcome score and the amount of restoration of Bohler's and Gissane angle. The more the correction of angle near normal, the better the functional outcome. Similar observations were found in other studies. ${ }^{18,20}$ In a review of 70 cases of displaced intra-articular fracture of calcaneum done by Paul et al, they reported that patients had good clinical outcome after operation when Bohler's angle is optimally restored to $>10$ degree. ${ }^{25}$

In our study most of the patients (88.4\%) had sander's type II and type III fracture. Only three (11.6\%) had sander's type IV fracture and all patients had fair outcome in short term follow up. We do not have long term follow up of these patients. The treatment of sanders type IV is debatable. In sanders type IV fracture, the chance requirement of additional surgery is as high as $73 \% .^{10}$ It has been seen that risk of requirement subtalar arthrodesis is 5.5 times higher in sanders type IV than sanders type $\mathrm{II} .{ }^{15}$ To avoid second surgery in many of these patients, primary open reduction and internal fixation and subtalar fusion is good option.

Bone grafting of void created after elevation of articular fragment of calcaneum is controversial. We did not use bone graft in our study patients. Studies done by different author did not find any healing problem of fracture and difference of functional outcome with or without bone grafting. ${ }^{21,22}$

The complications associated with extended lateral approach are wound dehiscence, flap necrosis and infection. In this study three cases had superficial wound 
infection(11.5\%) but all healed with local wound care. According to SooHoo et al, the rates of complications associated with extended lateral approach may be historically overstated and rarely any further surgical treatment is required to heal wound. ${ }^{23}$ In a retrospective study done by Manouk et al, in 191 patients with calcaneal fracture treated by open reduction and internal fixation, American Society of Anesthesiologists (ASA) classification other than 1 and absence of a closed suction drain placement were associated with increased rate of wound infection. ${ }^{24}$ So proper patient selection is important to avoid complications. We also found subtalar synovitis in two cases but improved with steroid injection.

\section{CONCLUSION}

Open reduction and internal fixation with calcaneal plates and screws of displaced intra-articular fracture of calcaneum through extended lateral approach provides excellent to good clinical and radiological outcome by restoring Bohlers angle, Gissane angle, height and width of calcaneum. Proper surgical skill for elevation and handling of periosteal cutaneous flap is required to avoid wound complications.

\section{LIMITATIONS OF THE STUDY}

The limitations of the present study were small sample size, shorter follow up time, lack of comparative group and lack of availability of AOFAS measurement tool in local language.

\section{CONFLICT OF INTEREST}

None

\section{FINANCIAL DISCLOSURE}

No benefits in any form have been received and will be received from commercial party related to the subject of this article.

\section{REFERENCES}

1. Mitchell MJ,McKinleyJC, RobinsonCM.The epidemiology of calcaneal fractures. Foot (Edinb) 2009;19(4):197-200.DOI:10.1016/j. foot.2009.05.001.

2. Zwipp H, Rammelt S, Barthel S. Calcaneal fractures-the most frequent tarsal fractures. TherUmsch2004;61:435-50. DOI: 10.1024/0040-5930.61.7.435.

3. StulikJ, StehlikJ, Rysavy M, et al. Minimally-invasive treatment of intra articular fractures of the calcaneum. J Bone Joint Surg $\mathrm{Br}$ 2006;88: 1634-41.DOI: 10.1302/0301-620X.88B12.17379.

4. Buckley R, Tough S, McCormack R, Pate G, Leighton S, Petrie D, et al. Operative compared with non-operative treatment of displaced intra-articular calcaneal fractures: a prospective,randomised, controlled multicentredtrial.J Bone Joint Surg Am 2002;84: 1733-44. DOI: 10.2106/00004623-200210000-00001.

5. Agren $\mathrm{P}-\mathrm{H}, \mathrm{WretenbergP,Sayed}$ _noor AS. Operative versus nonoperative treatment of displaced intra-articular calcaneal fractures: a prospective randomized controlled multi-center trial. J Bone Joint Surg Am 2013;95:1351-7.DOI: 10.2106/JBJS.L.00759.

6. Griffin D, Parsons N, Shaw E, Kulikov Y, Hutchinson C, et al. Operative versus non-operative treatment for closed, displaced, intra-articular fractures of the calcaneus: randomised controlled trial. BMJ. 2014;349:g4483.DOI: https://doi.org/10.1136/bmj.g4483.

7. Hsu AR, Anderson RB, Cohen BE. Advances in surgical management of intraarticular calcaneus fractures. J Am AcadOrthop Surg. 2015;23:399-407.DOI: 10.5435/JAAOS-D-14-00287.

8. Jiang N, Lin QR, Diao XC, Wu L, Yu B, et al. Surgical versus non surgical treatment of displaced intra-articular calcaneal fracture: a metaanalysis of current evidence base. Int Orthop. 2012;36:1615-22. DOI: 10.1007/s00264-012-1563-0.

9. Basile A. Operative versus nonoperative treatment of displaced intra-articular calcaneal fractures in elderly patients. J Foot Ankle Surg. 2010;49:25-32.DOI: 10.1053/j.jfas.2009.08.001.

10. Sanders R, Fortin P, DiPasquale A, Walling A. Operative treatment in 120 displaced intraarticular calcaneal fractures: results using a prognostic computed tomography scan classification. Clin Orthop 1993;290:87-95. PMID: 8472475.

11. Eastwood DM, Langkamer VG, Atkins RM. Intra-articular fractures of the calcaneum. Part II: open reduction and internal fixation by the extended lateral transcalcaneal approach. J Bone Joint Surg [Br] 1993;75-B:189-95.PMID8444935.

12. Kitaoka HB, Alexander IJ, Adelaar RS, et al. Clinical rating systems for the anklehindfoot, midfoot, hallux, and lesser toes. Foot Ankle Int 1994;15:349-53.PMID: 7951968
13. DeBoerAS, Van Lieshout EM, DenHartog D, etal. Functionaloutcome and patient satisfaction after displaced intra-articularcalcaneal fractures: a comparison among open, percutaneous, and nonoperative treatment. J Foot Ankle Surg 2015;54:298-305.DOI: 10.1053/j.jfas.2014.04.014

14. Zeman P, Zeman J, Matejka J, et al. Long-term results of calcaneal fracture treatment by open reduction and internal fixation using a calcaneal locking compression plate from an extended lateral approach. Acta ChirOrthopTraumatol Cech 2008;75:457-64.PMID: 19150004

15. Csziy M, Buckley R,Tough S, Leighton R, Smith J, McCormack R, et al. Displaced intra-articular calcaneal fractures: variables predicting late subtalar fusion.J Ortho Trauma 2003;17:106-12.DOI: 10.1097/00005131-200302000-00005.

16. Court-Brown CM, Schmied M, Schutte BG. Factors affecting infection after calcaneal fracture fixation. Injury2009;40:1313-1315.DOI: 10.1016/j.injury.2009.03.044.

17. Lakhey S, Manandhar RR, Pradhan RL, Pandey BK, Sharma S, Rijal KP. Functional outcome of operatively treated displaced intra-articular calcaneal fractures using two parallel contoured reconstruction plates. KUMJ. 2010;8(1):12-7.DOI: 10.3126/kumj.v8i1.3215.

18. Shrestha R, Shrestha D, Kayastha SR, Winker H. Displaced Intra-Articular Calcaneal Fractures: Evaluation of Clinical and Radiological Outcome Following Open Reduction and Internal Fixation with Locking Branched Calcaneal Plate. Kathmandu Univ Med J 2017;58(2):130-36.

19. Jain S, Jain AK, Kumar I. Outcome of open reduction and internal fixation of intraarticular calcaneal fracture fixed with locking calcaneal plate. Chinese J of Traumatology. 2013;16(6):355-60.PMID: 24295583.

20. D. Makki, H. M. Alnajjar, S. Walkay, U. Ramkumar, A. J. Watson, P. W. Allen. Osteosynthesis of displaced intra-articular fractures of the calcaneum- A LONG-TERM REVIEW OF 47 CASES. J Bone Joint Surg [Br] 2010;92-B:693-700.DOI: 10.1302/0301-620X.92B5.23542.

21. Letournel E. Open treatment of acute calcaneal fractures. Clin Orthop Relat Res1993;290:60-67.PMID: 8472472.

22. Yang $\mathrm{Y}$, Zhao $\mathrm{H}$, Zhou J, Yu G. Treatment of displaced intraarticular calcaneal fractures with or without bone grafts: a systematic review of the literature. Indian J Orthop2012;46:130-137.DOI:10.4103 /0019-5413.93672.

23. SooHoo NF, Farng E, Krenek L, ZingmondDS.Complication rates following operative treatment of calcaneus fractures. Foot Ankle Surg 2011;17:233-8.DOI: 10.12669/pjms.324.10225.

24. ManoukBackes, Tim Schepers\& M. Suzan H. Beerekamp\& Jan S. K. Luitse\& J. Carel Goslings \& Niels W. L. Schep International Orthopaedics (SICOT) (2014;38:767-773.DOI: 10.1007/s00264-013-2181-1.

25. Paul $M$, Peter $R$, Hoffmeyer P. Fractures of the calcaneum: a review of 70 patients. J Bone Joint Surg [Br] 2004;86-B:1142-5. DOI: 10.1302/0301-620x.86b8.15219. 